\title{
THE IMPACT OF USING LOGO PROGRAMMING LANGUAGE ON THE DEVELOPMENT OF SPATIAL VISUALISATION ABILITY AMONG ELEMENTARY SCHOOL STUDENTS
}

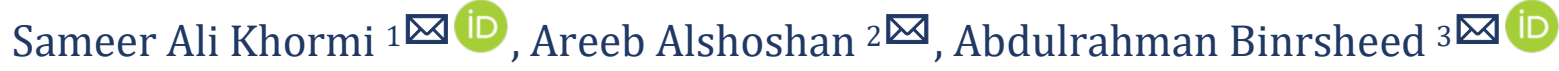 \\ 1 Teacher in General Directorate of Education in Jeddah, EdD candidate at Newcastle University \\ 2, 3 Al Imam Mohmmad Ibn Saud Islamic University, PhD candidate at Newcastle University
}

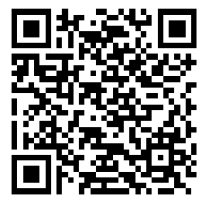

DOI: https://doi.org/10.29121/granthaalayah.v9.i3.2021.3771

Article Type: Research Article

Article Citation: Sameer Ali Khormi, Areeb Alshoshan, and Abdulrahman Binrsheed. (2021). THE IMPACT OF USING LOGO PROGRAMMING LANGUAGE ON THE DEVELOPMENT OF SPATIAL VISUALISATION ABILITY AMONG ELEMENTARY SCHOOL STUDENTS. International Journal of Research GRANTHAALAYAH, 9(3), 118-127. https://doi.org/10.29121/granthaa layah.v9.i3.2021.3771

Received Date: 01 March 2021

Accepted Date: 26 March 2021

Keywords:

LOGO

Teaching

Mathematics

Spatial Ability

\section{ABSTRACT}

This study aims to investigate the effect of using LOGO on the improvement of spatial visualisation abilities among fourth-grade elementary students. In order to achieve this objective, the researchers have selected the Arabic version of spatial ability test prepared by Paul Newton and Helen Bristoll, which involves spatial visualisation perception. The researchers have employed the pre and post-test quasi-experimental approach. The research was applied to a sample group composed of 53 students enrolled in the fourth grade of the elementary stage. The sample group was selected from an elementary school-based in the city of Jeddah, Saudi Arabia. Members of the sample group were randomly and simply divided into two groups; specifically the experimental and control groups. The experimental group was taught using LOGO programming language, while the control group was taught using the traditional method. After implementing the research treatment and processing data and information statistically, findings revealed that there are statistical differences between the two groups; namely, the experimental and control groups - in terms of the development of spatial visualisation perception in favour of the experimental group.

\section{INTRODUCTION}

Due to the breakthrough in technology which has shed light on all aspects of life, technology has become part and parcel of modern societies. In addition to the recent developments in technology, is computer sets that have been employed in various fields connected with education. Computers can be used in several fields as an educational subject and an assisting tool in education.

Accordingly, the computer has become an effective element in the educational environment since it largely contributes to the improvement of students/pupils' intellectual skills enrolled in the elementary stage (Saleh, 2006).

Therefore, many techniques and methods have been created to help students develop new innovative patterns of thought; hence, helping them learn about different situations that require the use of logic and analysis. Subsequently, intellectual capabilities will be further developed and improved.

(C) 2021 The Author(s). This is an open access article distributed under the terms of the Creative Commons Attribution License, which permits unrestricted use, distribution, and reproduction in any medium, provided the original author and source are credited. 
Among these methods through which students' intellectual and thought capabilities could be improved and developed is LOGO or Mathematics of Turtles. In fact, LOGO was initially developed in an artificial intelligence laboratory at the Massachusetts Institute of Technology (MIT). LOGO was developed by the MIT mathematician and computer scientist Seymour Papert in 1970. LOGO's paramount objective was to educate and teach children about geometrical drawings (Papert, 1988).

LOGO is considered a means of thinking that is easily programmable and through which children may learn about types and patterns of geometrical drawings. Moreover, owing to that fact, geometry is viewed as a means of thinking that provides organised serial knowledge. Moreover, Hover claimed that the significance of geometry is represented by being a subject affiliated to intellectual structure (Al-Saeed, 2007).

LOGO is characterised by way of its simplicity and entertainment. It has commands and structures that match mathematical symbols and structures, that in turn, encourage a connection between visual representation and symbols. It further enables a relationship between spatial ability on the one hand and numerical ability on the other. Besides, it allows the students to learn through trial-and-error, exploration and a research approach. It further reflects mathematical thinking in general and geometrical thinking in particular. It is a method used for learning about mathematical concepts, such as logic, geometry and mathematics. It further helps understand the intuitive ideas associated with geometry. LOGO is regarded as an interactive language that reacts immediately to commands. It is not just a language concerned with geometrical drawings, but rather a culture, philosophy, logic, education and learning (Mecdashi, n.d; Al-Hazmi, 1995; Martin \& Paulsen \& Prata, 1985; Clements \& Sarma, 1999).

By learning geometry, learners can discover the relationship between shapes. The latter could develop spatial ability in general and spatial visualisation in particular. The researche believe that a weakness in such ability is regarded as one of the reasons behind low academic attainment in mathematics in general and geometry in particular. This relationship regarding the theoretical connections between spatial visualisation and academic attainment in mathematics was established in studies conducted by Rock et al. The results of these studies and research have revealed that different aspects of mathematical thinking are apparently correlated with both spatial visual representations and linguistic representations (Ziyada, 2006). Graf emphasised the connection between spatial visualisation and the difficulties likely to be confronted by the student when learning mathematics in general and geometry in particular and stressed that the student's academic attainment could be adversely affected (Graf, 2010).

Moreover, Gal and Linchevski contended that one of the most outstanding reasons behind geometry difficulties could be attributed to the ineffective ability of visual representation (Gal \& Linchevski, 2010). Yue further asserted that spatial visualisation is considered a fundamental skill that could be classified under the skills of drawings and geometrical designs (Yue, 2007). What really supports the importance of visualisation in teaching geometry is Van Hell's Levels of Geometrical Thinking. The first stage of those specific levels is visualisation. Moreover, focusing on improvement and the development of visualisation contributes to the improvement and development of mathematics effectively rather than only focusing on mathematical content and skills (Baker \& Belland, 1986).

Psychology of Mathematics Education (PME), emphasised the relationship between spatial ability and learning about geometrical concepts by way of visual methods (PME, 2006). Furthermore, Silverman highlighted the importance of using computers to improve and develop spatial visualisation ability (Silverman, 2011). Clements and Sarama (2005), quoting Piaget and Inhelder (1967), stated that geometrical and spatial relationships should be learned through body motions.

Thanks to the importance of spatial visualisation in particular and spatial ability generally, in connection with learning and teaching geometry, the National Council of Teachers of Mathematics (NCTM, 2000), underscored the importance of the inclusion of standards of geometry and spatial ability, alongside the use of computer software such as LOGO, to represent spatial and geometrical concepts (Georgans, 2009).

Several studies have been conducted in order to recognise the methods through which spatial ability could be improved and developed. Among these studies was the study conducted by Al-Bassiouni (1994). The latter study aimed to recognise the effect of teaching methods (data processing, symbol processing) on academic attainment by students who have a certain level of spatial ability and ability to comprehend symbols during their study, so as to solve equations and inequalities with definite functions and the intention to predict such abilities in connection with attainment in mathematics. The research concluded that there was an abnormal statistical interaction between spatial ability and the two processing methods employed. The researchers also concluded that there was a direct relationship with statistical indication between the student's spatial ability and academic attainment when 
The Impact of Using Logo Programming Language on the Development of Spatial Visualisation Ability Among Elementary School Students

employing spatial ability. Specifically, the prediction of academic attainment and solving equations and inequalities could be achieved via spatial ability.

The research conducted by Mohammed and Al-Nouaimy (1992), aimed to understand the effect of using animation in improving and developing the skills of recognising spatial ability among fifth grade elementary students in Qatar. The research further aimed to determine if there are any differences in relation to gender/sex. The findings revealed that there was a statistically indicated difference between the average student's acquisition of spatial ability skill in favour of the experimental group. This was attributed to training by means of watching animation. Similarly, the study concluded that there was no statistically indicated difference between males and females in terms of average acquisition of spatial ability skills. Furthermore, the study revealed that there was a statistically indicated difference that referred to the interaction between animation programs with gender in favour of male students.

Within the same context, another study was carried out by Al-Ameri (1999), which intended to identify and understand "the effect of the use of LOGO-programmed computer on teaching geometrical concepts in mathematics and the extent of development of spatial ability among learners using computers". The findings obtained by this study revealed that there was a statistically indicated difference between the experimental group on the one hand and the control group on the other, in terms of average performance in the examination of geometrical concepts and spatial ability.

Regarding factors impacting spatial ability, Cassity (1997), conducted a study to investigate the relationship between the following factors among males and females: spatial ability, mathematical confidence, fundamental ability in algebra and classrooms use of the calculators and graphs used in the computers at the College of Algebra. The study's findings revealed that spatial visualisation variables and mathematical confidence were correlated to the performance of mathematical concepts when using calculators and graphs as tools.

Boakes conducted a study that tracked and investigated the effect of teaching by using origami instructions (the Art of Folding Papers) in mathematics classes at intermediate schools (Boakes, 2009). The study focused on the origami effect of being an educational tool to teach mathematics in intermediate school classrooms. The findings showed that there were no statistically indicated differences between teaching by using origami instructions and geometrical knowledge. The study also revealed that origami instructions had a different impact on spatial ability among males and females.

Considering the educational literature, a dire need for a tool to improve and develop spatial visualisation ability was apparently observed. Therefore, the researchers believe that a study must be conducted to measure the effect of the use of LOGO on the improvement of spatial visualisation ability among fourth grade elementary students based in the city of Jeddah.

\section{RESEARCH PROBLEM AND QUESTIONS}

Upon considering the literature review and the process of teaching mathematics, the researchers observed that the students might have difficulties recognising the geometrical illustration after carrying out a geometrical conversion, such as retraction, rotation or symmetry. A large number of students failed to identify and recognise geometrical drawings, or even mixed them up. Moreover, students experienced difficulties in identifying the relationships between such geometrical drawings.

Furthermore, the researchers observed that a few studies had explored spatial visualisation and LOGO as a tool that could be used to improve and develop spatial visualisation ability. From this point and in light of the importance of geometry among other mathematics-related topics, as well as the importance of geometrical concepts in the field of spatial abilities, specifically spatial visualisation, the researchers believe that there is a definite need for a tool to improve spatial visualisation ability among students. Given that effectiveness in improving spatial visualisation ability could be achieved through visual methods, then LOGO could be used within this context. Accordingly, this research attempts to provide an answer to the main question indicated below:

"What is the effect of using LOGO on improving and developing spatial visualisation among fourth grade elementary students?" 


\section{RESEARCH SIGNIFICANCE}

This research derives its significance from a research topic which revolves around searching for a tool that would improve spatial visualisation ability in addition to the importance of improving and developing the spatial visualisation of geometrical drawings by the use of computers in teaching mathematics as being an effective trend in teaching mathematics. Hence, students would be able understand the concepts of geometry and eventually increase their levels of academic attainment as regards geometry.

\section{RESEARCH OBJECTIVES}

This research aims to investigate the effect of teaching through the use of LOGO on improving spatial visualisation ability among students enrolled in the fourth grade of the elementary stage.

\section{RESEARCH HYPOTHESES}

There are no statistically indicated differences at the level of $(\alpha \leq 0.05)$ between the experimental group and control group in the improvement of spatial visualisation ability, while studying the identification and description of the geometrical shapes unit by using LOGO in the post application of fourth grade students at an elementary school in Jeddah in favour of the experimental group.

\section{RESEARCH TERMS}

\subsection{LOGO PROGRAMMING LANGUAGE}

This particular language was developed by Seymour Papert to assist students enrolled in the elementary stage of education to understand geometrical concepts according to Piaget's stages of intellectual perception of coexistence with mathematics. The first version of LOGO was introduced in 1970.

In Greek, the term "LOGO" means "thought". However, the language of LOGO is considered to be an artificially intelligent language. It is described as a language concerned with drawings and shapes dedicated to children and young people. It has unlimited potential and capabilities as it is suitable for all age groups and intellectual stages along with the students' thinking levels. The language employed in LOGO is similar to chess. The main character in LOGO is the "Turtle" which is displayed on the screen so as to execute commands and instructions given to it. As a learning environment concerned with understanding concepts related to geometry, LOGO depends on the trail-anderror basis (Al-Sebareni, 1999).

Papert (1988) believes that LOGO is an exploratory tool that would be used to correlate between learning child about language, learning mathematics, and learning thought through thought.

At the procedures level, it is worth noting that LOGO for teaching is a programming language provided by a computer set. The teacher could use LOGO to teach the concepts related to geometry according to the handbook prepared by the researchers.

\subsection{SPATIAL VISUALISATION ABILITY}

Spatial Visualisation can be defined as the ability to perform the intellectual or physical processing of objects which involves a certain series of moves. Frequently, the examinee finds that it is necessary to rotate one or more drawings or even part of an illustration, by overturning or tilting an illustration. The examinee will recognise the position, the new location, or the new shape belonging to the object(s) being subject to movement or modification inside a complex illustration/drawing (Badr, 2000).

Aa per Abu Hatab (1986), spatial visualisation is the ability to understand and comprehend the imagined motion in a 3-dimensional (3D) location or the ability to process objects in the imagination. While, The Dictionary of Psychology defined spatial visualisation as the perception and recognition of spatial relations (Zahran, 1987).

According to The Encyclopaedia of Psychology, spatial visualisation can be defined as the ability to use or convert an illustration or drawing into another visual organisation or the ability to introduce or create a number of 
The Impact of Using Logo Programming Language on the Development of Spatial Visualisation Ability Among Elementary School Students

changes and modifications into visualised objects and the ability to imagine motion and spatial replacement of an illustration or part of it (1998).

In the eyes of Barakat (2006), spatial visualisation is incorporated in the individual's ability to perform a set of visual activities which cover recognition and the perception of relationships between a number of objects; the perception of such objects when looking at them from different aspects as well as fixing or administering such in 2D or 3D. According to Al-Malki (2009), spatial visualisation can be defined as an intellectual cognitive activity which is characterised by the spatial visualisation relating to the movement of objects and bodies in space. It depends on the recognition of the geometrical relationships between shapes, objects, velocity and accuracy and the use or conversion of such object into another visual organisation or even the introduction of a number of changes or modifications into visualised objects.

At the procedures level, spatial visualisation can be defined as the mark acquired by the student in the examination of spatial visualisation which was firstly developed by Paul Newton and Helen Bristoll (2009). The examination of spatial visualisation was translated by the Khormi (2012).

\section{RESEARCH METHODOLOGY AND DESIGN}

This research employed quantitative research. The researchers adopted a pre and post-test quasi-experimental design, which divided the sample group into two groups: an experimental group and a control one. The experimental group was subject to processing by means of an independent variable in this study, which is "Teaching through the Use of LOGO" so as to measure the effect of the said variable on the dependent variable embodied in the "Ability of Spatial Visualisation". However, the control group was not subject to processing and had been taught conventionally. The researchers proceeded to submit the pre-test to the two groups - namely, the experimental and control groups prior to processing. After processing, the researchers conducted the post-test on the two groups so as to investigate the effect of processing. Hence, the researchers intentionally selected the quasi-experimental design which is called a design for two equal groups with frequent application (pre and post). The following table highlights the design of the present research.

Table 1: Research Design

\begin{tabular}{|c|c|c|c|}
\hline & Pre-Test & Treatment & Post-Test \\
\hline Experimental group & 01 & $\mathrm{X}$ & 02 \\
\hline Control group & 01 & $* * * * * * * * * * * * * * * *$ & 02 \\
\hline
\end{tabular}

\section{RESEARCH POPULATION AND SAMPLE}

The research population was composed of all students enrolled in the second semester of the fourth grade of an elementary school based in the city of Jeddah during the school year 2019/2020). According to the statistics issued by the General Directorate of Education in Jeddah Province, 54380 students were registered. After identifying and defining the research population, the researchers selected the sample group from schools affiliated to the General Directorate of Education in Jeddah by mean. The school was selected according to the availability of computer sets in the school and the cooperation of the school administration and teachers with the researchers.

However, the sample group was simply and randomly selected. The sample group was composed of 53 students (i.e., 27 students in the experimental group and 26 students in the control group).

\section{EQUIVALENCE OF GROUPS}

The researchers conducted a pre-test in order to examine the ability of spatial visualisation on the two groups - i.e., the experimental and control groups. The researchers conducted this pre-test in order to examine the equivalence between both groups prior to applying the experiment. The findings revealed the following: 
Table 2: The illustration below refers to the indicative differences between the average marks acquired by students in both the experimental and control groups in the spatial ability pre-test

\begin{tabular}{|c|c|c|c|c|c|c|}
\hline Group & $\begin{array}{c}\text { Number of } \\
\text { Students }\end{array}$ & $\begin{array}{c}\text { Arithmetic } \\
\text { Mean }\end{array}$ & $\begin{array}{c}\text { Standard } \\
\text { Deviation }\end{array}$ & $\begin{array}{c}\text { “T” } \\
\text { Value }\end{array}$ & $\begin{array}{c}\text { Freedom } \\
\text { Marks }\end{array}$ & $\begin{array}{c}\text { Indication } \\
\text { Level }\end{array}$ \\
\hline Control & 24 & 18,48 & 8,223 & 0,158 & 48 & 0.875 \\
Experimental & 27 & 18,08 & 9,174 & & & $\begin{array}{c}\text { Non- } \\
\text { Indicative }\end{array}$ \\
\hline
\end{tabular}

In Table (2), there are no statistically indicated differences (at the level of $\alpha \leq 0.05$ ) between the two groups in terms of average marks obtained by students in the examination of spatial visualisation ability in the pre-test. This signifies that both groups are equal in terms of spatial visualisation ability.

\section{RESEARCH INSTRUMENT}

As the present study aims to identify and recognise the effect of teaching using LOGO on spatial visualisation among students enrolled in the fourth grade in an elementary school in Jeddah, the researchers selected the Spatial Ability Test for Paul Newton and Helen Bristoll, which was translated by Khormi (2012).

\section{RESEARCH PROCEDURES}

To conduct the study, the researchers followed the procedures below:

1) To be familiar with the literature review, research and previous studies related to the theme of the study

2) To select the Spatial Ability Test

3) To limit study population and identify the sample group deliberately

4) To secure permission(s) from competent authorities to conduct the research/study

5) To identify and define the elementary school in Jeddah which is intended to be the subject of the study and to further identify the two experimental and control groups.

6) To carry out a pre-test on the Spatial Ability Test so as to verify the equivalence of both groups

7) To prepare the teacher's handbook for the experimental group so that it can be employed when teaching topics selected from the mathematics curriculum prescribed for students enrolled in the fourth grade of the elementary stage of education by using LOGO. The manual is prepared by the researchers.

8) To train the teacher participating in the experiment

9) To implement the research on the experimental group where they will be taught to describing geometrical drawings and shapes using LOGO, while the control group will be taught using a traditional method

10) To apply the Spatial Ability Test as a dimensional test so as to identify and recognise the effect of LOGO on the improvement and development of students' spatial visualisation ability

11) To monitor the findings and process of such findings statistically by using SPSS

12) To analyse and interpret the findings

13) To provide recommendations

\section{METHODS OF STATISTICAL PROCESSING}

According to the nature of the research and the objectives expected to be achieved, data and information will be analysed by employing SPSS as per the statistical methods indicated below:

1) Frequencies, averages and standard deviations

2) Independent Samples T-Test

3) Cronbach's Alpha to verify the reliability of the test

4) Split Half to verify the reliability of the test

5) Calculation of the effect size by way of calculating the square eta and the use of the following formula:

$$
\eta^{2}=\mathrm{T}^{2} /\left(\mathrm{T}^{2}+\text { Freedom Mark }\right)
$$


The Impact of Using Logo Programming Language on the Development of Spatial Visualisation Ability Among Elementary School Students

Where $\mathrm{T} 2$ is the square value of $\mathrm{T}$ of the difference between both averages

\section{RESEARCH FINDINGS \& DISCUSSION}

This research aims to provide an answer to the following question:

Are there any statistically indicated differences (at the level of $\alpha \leq 0.05$ ) between the experimental and control groups in terms of the development and improvement of spatial visualisation to identify geometrical shapes and drawings and describe them in the dimensional application among students enrolled in the fourth grade of elementary school in Jeddah in favour of the experimental group?

The findings obtained revealed the following:

Table 9: The table below indicates differences between the average marks obtained by students in the experimental and control groups in the dimensional application of the Spatial Ability Test in identifying and describing geometrical shapes and drawings

\begin{tabular}{|c|c|c|c|c|c|c|c|}
\hline Group & $\begin{array}{c}\text { Number of } \\
\text { Students }\end{array}$ & Mean & $\begin{array}{c}\text { Standard } \\
\text { Deviation }\end{array}$ & $\begin{array}{c}\text { "T" } \\
\text { Value }\end{array}$ & $\begin{array}{c}\text { Freedom } \\
\text { Marks }\end{array}$ & $\begin{array}{c}\text { Indication } \\
\text { Level }\end{array}$ & $\begin{array}{c}\text { Volume of } \\
\text { Effect }\end{array}$ \\
\hline Control & 22 & 23 & 6,54 & 2,1 & 46 & 0,04 & 0.09 \\
\cline { 1 - 7 } Experimental & 25 & 26.84 & 6,12 & & & & Average \\
\hline
\end{tabular}

According to Table (9), students in the experimental group surpass those in the control group in terms of the improvement and development of spatial visualisation related to geometrical drawings and shapes in dimensional application. Students classified under the experimental group obtained an average mark of 26.84, which is equivalent to $9.6 \%$ of the total marks obtained by the students in the Spatial Ability Test. Conversely, students classified under the control group obtained an average mark estimated to be 23 , which is equivalent to $1.1 \%$ of the total marks acquired by the students in the Spatial Ability Test. Table (9), confirms that there are statistically indicated differences (at the level $\alpha \leq 0.05$ ) between the experimental and control groups in terms of the improvement and development of spatial visualisation related to the identification of geometrical drawings and shapes and the description of such in the dimensional application among students enrolled in the fourth grade of an elementary school based in Jeddah, in favour of the experimental group.

To identify the effect size of teaching using LOGO with the aim to improve and develop the spatial visualisation related to the identification of geometrical drawings and shapes and the description of such in the dimensional application, the square of eta $\eta 2$ as indicated in Table (9), was calculated. The volume of the effect of processing stands at 0.09. It is regarded as a mean value. This indicates that teaching through the use of LOGO has a positive effect regarding the improvement and development of spatial visualisation. Accordingly, the research question has been answered.

Based on what has been previously mentioned, it is somewhat evident that spatial visualisation ability has been improved and developed among students classified under the experimental group in a statistically indicative manner. It should be noted here that the researchers attribute the excellence of students classified under the experimental group in spatial visualisation to teaching through the use of LOGO. The effect size of the research experiment between both the experimental and control groups is 0.09 , which is considered a mean value. Therefore, teaching through the use of LOGO would lead to the achievement of positive findings in terms of the improvement and development of spatial visualisation ability.

Such findings concur with the study completed by Al-Ameri (1999), which highlighted that the use of computers programmed with LOGO in teaching would help to improve and develop students' spatial ability - compared to conventional teaching methods. In contrast, studies conducted by Al-Bassiouni (1983), Mohammed and Al-Nuaimei (1992) and Boakes (2009), revealed that visual processing has an effect on the spatial intellectual ability. Studies mentioned previously further confirm that visual processing is considered to be an additional factor to improve and develop spatial ability in general. Consequently, spatial visualisation, as one of the components of spatial intellectual ability, improves and is affected by visual processing. As LOGO is regarded as visual processing, it acts on improving and developing spatial visualisation as indicated by the findings mentioned above. 
The researchers attribute the brilliance of the students classified under the experimental group in terms of spatial visualisation ability to the following causes.

1) Visual processing is considered a means through which spatial visualisation ability could be improved and developed. Since LOGO is regarded as visual processing, it could also be considered a tool to improve spatial visualisation ability as the student employs LOGO to draw geometrical shapes and drawings. In addition, the student resorts to imagining the geometrical illustration to draw it and further embodies the role of turtle during the drawing process.

2) LOGO helps the student improve and develop the ability to use their imagination, by using by mental pictures of various geometric shapes that were acquired by students through their learning process. The student further embodies the character of a turtle and mentally imagines its movement(s).

3) LOGO improves the student's ability to analyse geometrical shapes and drawings, as well as the ability to recognise its components and discriminate between various shapes. It further improves the student's ability to collect and match geometrical shapes and drawings so as to compose a new geometrical illustration. In turn, that will result in an improvement and the development of spatial visualisation ability as LOGO acts on improving the skills composing spatial visualisation ability.

4) LOGO improves the student's ability to discriminate between geometrical shapes and drawings in all its various positions. It has been observed that most students managed to answer the section dedicated to Spatial Ability extremely well. The performance of the students in this section was higher than that of other sections - indicating that LOGO has an effective role in the improvement and development of spatial visualisation ability.

5) Concentration and focus on the skills and details of geometrical shapes and drawings executed through the use of LOGO is viewed as an aspect that could improve and develop spatial visualisation ability and geometry-related attainment due to the student's use of LOGO. In fact, LOGO depends on the skills when composing the geometrical illustration. When the student draws any geometrical illustration, he/she gives commands to LOGO in detail in order to carry out these commands. Hence, the student's ability to recognise, analyse and re-collect the components of geometrical shapes and drawings is improved and developed. Moreover, the student's ability to compose relationships between different geometrical shapes and drawings is also improved and developed. It should be stated that this was quite obvious when the students proceeded to carry out the latter activity during the research. Responses reflected the extent of the accuracy of inference and observations concerning the geometrical shapes and drawings they executed.

The researchers believe that the growth witnessed in the ability of spatial visualisation attributed to teaching by applying LOGO led to growth in geometry-related attainment since the skills and components of spatial visualisation ability are interconnected with the concepts of geometry. These could be considered supportive factors to comprehend and understand the concepts of geometry. The growth that occurred in relation to such skills and components has led to growth in geometry attainment.

Likewise, it could be said that visual processing, directed by LOGO, serves to improve and develop spatial visualisation and geometry attainment positively. The employment of visual processing represented by LOGO in the mathematics curriculum would lead to an improvement in the performance of students in mathematics.

\section{RESEARCH RECOMMENDATIONS}

In light of the findings concluded by the present study, the researchers make the following recommendations:

1) Training courses should be provided to teachers and educational supervisors with the aim of improving and developing their performance in using LOGO so that they are able to teach geometrical shapes and drawings.

2) Mathematics curricula should include LOGO-based activities thanks to its importance in improving and upgrading spatial visualisation.

3) The requirements necessary for teaching by employing LOGO will be provided so as to improve and upgrade spatial visualisation. 
The Impact of Using Logo Programming Language on the Development of Spatial Visualisation Ability Among Elementary School Students

\section{SOURCES OF FUNDING}

This research received no specific grant from any funding agency in the public, commercial, or not-for-profit sectors.

\section{CONFLICT OF INTEREST}

The author have declared that no competing interests exist.

\section{ACKNOWLEDGMENT}

None.

\section{REFERENCES}

[1] Abu Hashem, Al-Sayed. (2004). Statistical Guide in Data Analysis by use of SPSS. Riyadh, Al-Rushid Library

[2] Abu Hatab, Fouad. (1986). Intellectual Abilities. Cairo: Anglo House, Egyptian

[3] Al-Ameri, Akram (1999). Effect of Use of Computer Programmed with LOGO on Learning Geometry Concept in Spatial Ability Field - Future Studies, 4, pp. 125-150

[4] Al-Bassiouni, Mohammed (1994, January): A Study on Interaction between Spatial Ability and Comprehension of Symbols; and Two Processes in Teaching Solution of Equations and Definite Value Function Inequalities: The Second Scientific Registry, 1979/1983, Mansoura, University of Mansoura

[5] Al-Hazmi, Mutlaq (1995). Mathematics and Computer. Riyadh: Arab Education Office of Gulf States

[6] Al-Malki, Awad (2009). Relationship between Spatial Visualisation in Mathematics and Technical Skill among Male and Female Students Enrolled in the Intermediate/Preparatory Second Grade, Makkah: Mathematics Educations, Volume Twelve, pp. 167-202

[7] Al-Saeed, Redman (2007). Extent of Reliability of Geometry Content in Mathematics Textbooks 7-9 in Republic of Yemen with Educational Fundamentals of Van Hell's Theorem of Geometry Thinking, Educational and Psychological Science Journal, 3, pp. 165-185

[8] Badr, Mahmoud (2000). Proposed Curriculum in LOGO and its applications; and its relationship to spatial visualisation; Control Centre for Computer Department Students, Level III, Teachers' College, Riyadh, Studies in Curriculums and Teaching Methods, 65, pp. 150-181

[9] Baker, P; Belland; J. (1986). Developing Spatial Skills with ExperLOGO on the MacIntosh. Information Analyses, Opinion Papers, Speeches Meeting Papers. (Eric Document Reproduction Service No. ED281490)

[10] Barakat, Ahmed (2006), Effectiveness of Spatial Visualisation Introduction in Improvement of Some Dimensions of Spatial Ability and Attainment among Students of Preparatory Stage of Education in the Subject of Science, MA Thesis unpublished, Department of Curriculums and Teaching Methods, Girls' College, Ain Shams University, Cairo

[11] Boakes, Norma J. (2009). Origami Instruction in the Middle School Mathematics Classroom: Its Impact on Spatial Visualisation and Geometry Knowledge of Students. RMLE Online Research in Middle Level Education, 32 (7), 1-12.

[12] Cassity, Constance L. (1997). Learning with Technology Research on Graphing Calculators. Reports, Research, Speeches, Meeting Papers (Eric Document Reproduction Service No. Ed409880)

[13] Clements, Douglas; Sarama, Julie (1999, Spring). Research and Mathematics Education Standards. Logo Exchange, Volume 17(3). pp. 27-30

[14] Clements, Douglas; Sarama, Julie (2005). Young Children and Technology: What's Appropriate? In Masalski, Willian; Elliot, Portia (Editor). Technology-Supported Mathematics Learning Environment Sixty Seven Yearbook. National Council of Teachers of Mathematics (pp.51-73) US: NCTM

[15] Edito Crips International Authority (1998): Encyclopaedia of Psychology, Volume 4, Encyclopedia of Psychology, Volume 4 (Ed. 1); Beirut: Edito Crips International 
[16] Gal, Hagar; Lincheveski, Liora (2010, June). To see or not to see: Analysing Difficulties in Geometry from the Perspective of Visual Perception. Educational Studies in Mathematics. Volume 74 (2), pp. 163-183

[17] Georgans, Suzan (2009). Teaching Mathematics for Students Having Learning Difficulties (Translated by Ramadan Badawi). Amman, Dar Al-Fikr

[18] Graf, Anderea B. (2010, September). Think outside the Polygon. Mathematics Teaching in the Middle School, Vol. 16 (2), pp. 82-87

[19] International Group for the Psychology of Mathematics Education "PME" (2006). Handbook of Research on the Psychology of Mathematics Education Past, Present and Future. Rotterdam: SENSE PUBLISHERS

[20] Martin, Donald; Paulsen, Marijane; Prata, Stephen (1985). IBM PC and PCjr Logo Programming Primer. Indianapolis; H.W. Sams

[21] Mekdashi, Omar: Encyclopaedia of Electronic Programming with LOGO: Beirut, Dar Al-Rateb, without date

[22] Mohammed, Mostaf, Al-Nuaimei, Najah (1992). Effect of Use of Animation on Improvement and Development of Spatial Ability among Students Enrolled in the Elementary Fifth Grade in Qatar. Educational Research Centre Journal, Qatar University 2, pp. 9-37.

[23] Papery, Seymour, (1988). Intellectual Storms, Computer, Children and Strong Thoughts, Everything about LOGO: How was invented and How it works. Translated by Mohammed Al-Malaq, Riyadh, King Saud University Print

[24] Saleh, Majeda (2006). Contemporary Trends in Teaching Mathematics. Amman: Dar Al-Fikr

[25] Silverman, Linda. (2011). Effective Techniques for Teaching Highly Gifter Visual-Spatial Learners. Available at www.gifteddevelopment.com/Articles/vsl/v05.pdf

[26] Yue, Juanping. (2007). Spatial Visualisation by Isometric View. Journal Articles, Report.

[27] Ziyadah, Khalid. (2006). Difficulties of Learning Mathematics (Dyscalculia). Cairo: Etrack House for Printing, Publishing and Distribution

[28] Khormi, Sameer. (2012). Effect of LOGO-Based Instruction on the Development of Geometric Performance and Spatial Visualization Ability among Fourth Elementary Class Students. Master thesis. King Saud University. 